\title{
Introdução à antropologia das compras
}

\author{
Tiago Eloy Zaidan ${ }^{1}$ \\ ${ }^{1}$ Faculdade Joaquim Nabuco, e-mail: hector.montiel@udlap.mx
}

\begin{tabular}{|c|c|}
\hline & ARTICLE REVIEW \\
\hline Received 29.12.14 & UNDERHILL, Paco. Vamos às compras!: a ciência do consumo nos mercados globais. \\
\hline $\begin{array}{l}\text { Revised 23.03.15 } \\
\text { Accepted 06.04.15 }\end{array}$ & Trad. Ricardo Bastos Vieira. Rio de Janeiro: Elsevier, 2009. 317 p. \\
\hline
\end{tabular}

DOI:10.7867/1980-431.2015v20n1p3_46

ISSN1980-4431

Double-blind review (c) (i) ()

Fundador da consultoria para o varejo Envirosell, a qual estuda aspectos relacionados à antropologia do consumo, Paco Underhill é considerado um dos vanguardistas do que vem se chamando de ciência das compras. Segundo o próprio autor, tal campo de estudo abrange, dentre os seus objetivos e problemas:

Como criar cartazes que as pessoas leiam. Como se assegurar de que todas as mensagens estejam no local apropriado. Como criar mostruários que o shoppers possam manipular com facilidade e conforto. Como assegurar que os shoppers percorram - e desejem percorrer - todos os cantos da loja (UNDERHILL, 2009, p. 28).

Na obra Vamos às compras!, o termo shopper nomina aquele que está fazendo compras no ambiente de varejo.

Embora o livro não se atenha a questões epistemológicas, a pesquisa de Underhill baseiase, cientificamente, nas contribuições da etnografia, método marcante da antropologia social que não prescinde do fieldwork, a pesquisa de campo. Se o pesquisador polonês naturalizado britânico, Bronislaw Malinowski (1884-1942), foi a campo observar de perto os nativos de Trobriand, na Oceania, na década de 1920 (JAIME JR., 2001, p.70), o que faz a antropologia do consumo é observar os shoppers em seu habitat: o ambiente de compras.

Pode-se considerar o trabalho $A$ dimensão oculta, de Edward T. Hall (1914-2009), como um precursor importante da área. A obra, aqui resenhada, não se trata, portanto, propriamente de uma novidade. Para alguns estudiosos,

(...) os trabalhos de Hall inauguram uma abordagem antropológica dos domínios do consumo relativos ao espaço: a arquitetura, o mobiliário, a decoração interior, as cores, a iluminação, a climatização, as vestimentas, os transportes coletivos, os lugares de trabalho, os espaços de lazer, as vias públicas, etc. (JAIME JR., 2001, p.70).

O principal instrumento de coleta de dados propugnado pelo CEO da Envirosell é o track sheet. Trata-se de uma espécie de formulário, no qual um pesquisador de campo - incógnita aos olhos dos consumidores - anota tudo o que é possível monitorar dos passos dos clientes. Também são feitas filmagens.

Durante a pesquisa, a discrição é uma necessidade. Assim, o ideal é que os pesquisadores ou filmadoras não sejam notados pelos compradores, o que poderia alterar o comportamento destes - considerando o Princípio da Incerteza de Heisenberg. A julgar pelos flagras de furtos notados durante as pesquisas (UNDERHILL, 2009, p.305), as estratégias de "camuflagem" dos monitores têm dado certo. Em todo caso, não há interferência. Durante o processo de pesquisa, há apenas a observação e o relato. Da mesma forma, Underhill (2009, p.306) garante que a privacidade das pessoas assistidas é preservada.

O monitoramento do trajeto dos consumidores em compras e do fluxo de pessoas nos diversos setores de um estabelecimento de varejo em horários determinados fornece informações sobre eventuais problemas de fluxo. Um diagrama de circulação identifica os chamados "pontos cegos" da loja, ou seja, os locais pouco visitados pelos clientes, o que indica uma falha de projeto ou de layout (UNDERHILL, 2009, p. 82). Em algumas 
situações, a fila de compradores diante de caixas registradoras mau posicionadas geram uma "barricada" a qual atrapalha o fluxo de pessoas, reduzindo o número de passantes em determinadas partes da loja (UNDERHILL, 2009, p.224).

As filas para pagar as compras, aliás, são umas das maiores responsáveis pela degeneração da experiência de um consumidor de varejo. O tempo de espera em uma fila, depois de certo ponto, tende a ser superdimensionado pelo shopper (UNDERHILL, 2009, p. 214-215).

Cada um dos objetos pesquisados pela consultoria fundada por Underhill traz consigo variáveis que tornam os resultados de um monitoramento exclusivos. São exemplos: diferenças populacionais, distintos segmentos comerciais, situação econômica, dentre outros. Ainda assim, existem semelhanças, espécies de constatações gerais que podem ser estendidos para a maioria dos casos (UNDERHILL, 2009, p. 43).

É o caso do conceito de zona de descompressão, quiçá uma das maiores contribuições das ciências das compras até o momento. $\mathrm{O}$ termo refere-se à breve região frontal das lojas, contígua a entrada do salão de compras. Metaforicamente tratada pelo autor como uma "pista de pouso", a zona de descompressão é a faixa crítica na qual as pessoas estão se adaptando à mudança de ambiente: do lado externo para dentro da loja. Enquanto estão imbuídas na transição, as pessoas tendem a estar mais desatentas e menos sujeitas a abordagens. Consequentemente, displays de mercadorias, cartazes, pontos de distribuição de folhetos e até mesmo pilhas de cestas de compras localizadas nesta área tendem a ser ignoradas. Um reposicionamento de três metros para dentro na localização pode fazer grande diferença no aproveitamento destes instrumentos, embora se reconheça que o tamanho da zona de descompressão seja variável. $\mathrm{O}$ autor frisa que portas automáticas, ou giratórias, por exemplo, contribuem para aumentar o tamanho desta região, uma vez que não contribuem para reduzir a velocidade do comprador. Cabe ao varejista se adaptar a esta área de transição e buscar, sempre que possível, "domá-la", para reduzir o seu tamanho (UNDERHILL, 2009, p.46-48).

Nesse sentido, uma das estratégias utilizadas por grandes varejistas é a disposição de chamativas pilhas de uma só mercadoria (como latas de Coca-Cola, por exemplo), as quais funcionariam como uma espécie de redutor de velocidade, além de sugerir a possibilidade de fruição de um produto o qual pode ser encontrado, novamente, no interior da loja (UNDERHILL, 2009, p.49-50).

Outras descobertas curiosas: em ambientes apertados ou movimentados, um comprador em potencial - especialmente do sexo feminino - tende a desistir de examinar uma mercadoria e, consequentemente, de comprá-la, se for repetidamente roçado por trás. Mesmo que precise do produto
(UNDERHILL, 2009, p. 12). Por seu turno, o shopper que entra em uma loja tende a desviar-se para a direita, salvo algumas exceções culturais, como na Inglaterra. Tal tendência de movimento torna a parte frontal direita dos salões de compras uma área privilegiada (UNDERHILL, 2009, p.83$85)$.

Padrões distintos de comportamento entre shoppers do sexo masculino e feminino também foram identificados. A começar pelo uso de listas de compras. As mulheres se valem mais deste instrumento que os homens. Os homens, no corredor de uma loja, tendem a ser mais apressados, e, a depender do ambiente, dificilmente olham para algo se não possuem a intenção de comprá-lo. Os clientes do sexo masculino consultam menos a etiqueta de preço do que as mulheres. Entre os homens que provam roupas, $65 \%$ compram a peça que experimentaram. Já entre as clientes, apenas $25 \%$ realizam a compra da roupa provada (UNDERHILL, 2009, p.110-112).

Por fim, uma constatação feita em fastfoods. Enquanto os homens tendem a ser mais rápidos na escolha de uma mesa na parte frontal, com vistas para o salão, as mulheres gastam um pouco mais de tempo para escolherem suas mesas, e acabam optando pela parte de trás, supondo alguma privacidade (UNDERHILL, 2009, p.137).

Mais um fato sobre fast-foods: por volta de $10 \%$ dos clientes de drive-thrus consomem seus lanches no estacionamento da lanchonete, dentro de seus automóveis. Embora pudessem optar por utilizar o salão do estabelecimento (UNDERHILL, 2009, p.101).

$\mathrm{O}$ autor justifica a importância das pesquisas nos ambientes de varejo com o fato de que está cada vez mais difícil conquistar novos clientes:

A população não está crescendo significativamente e já temos mais lojas do que o necessário. O cálculo normal é que $80 \%$ das vendas advirão de $20 \%$ da clientela. Assim, se as lojas quiserem crescer, terão de descobrir como obter mais dos clientes existentes: mais visitas, mais tempo na loja, mais e maiores compras (UNDERHILL, 2009, p. 228).

Soma-se a isto o contexto de obsessão de redução de mão de obra como estratégia de redução de custos. Na medida em que se reduz funcionários nas lojas, aumenta-se as dificuldades do cliente em obter informações nos salões de compras. Com menos pessoal para tirar dúvidas e conduzir os shoppers, as lojas precisam cada vez mais tornar-se intuitivas e autoexplicativas, sobrecarregando o design, a promoção no ponto de venda e a formatação deste.

A bem da verdade, as pesquisas levadas a cabo pela consultoria de Underhill mostram que pelo menos parte das deficiências assistidas no varejo se devem à falta de valorização dos recur- 
sos humanos. Em um dos casos mencionados no livro, o pesquisador cita a desastrada decisão de um chefe de seção de uma loja de departamentos, o qual resolveu ampliar a área de exposição de mercadorias em detrimento do espaço destinado aos caixas. Em um local mais apertado e desconfortável, as funcionárias dos caixas passaram a sentir dores, cansaço e certa dose de irritação. Como consequência, a produtividade despencou. “(...) apontamos as filmadoras para as caixas registradoras e, de volta ao escritório, cronometramos as transações. Às $16 \mathrm{~h} 30 \mathrm{~m}$, registrar uma venda levava quase o dobro do tempo do que às 11h" (UNDERHILL, 2009, p.210).

Apesar da tendência de se "descartar" funcionários nos salões de venda, os estudos empreendidos concluíram que um simples contato encetado por um funcionário, o que inclui um lacônico "olá", aumenta probabilisticamente as chances do cliente comprar algo (UNDERHILL, 2009, p.181).

E aumentar as taxas de conversão dentre os visitantes das lojas e ampliar o volume de compras feitas por cada um dos shoppers é justamente o que se espera conseguir a partir das informações colhidas pelos "cientistas das compras". Trata-se de uma modalidade de pesquisa pragmática, como frisa o autor. E, nesta lida, vale inclusive cooptar as crianças. O livro sugere, por exemplo, que em alguns corredores de supermercados, sejam dispostos jogos, como uma simples amarelinha, desenhados no chão. A ideia é requerer a atenção da criança como forma de segurar os pais, por mais tempo, no corredor, evitando o que o consultor chama de efeito meio bumerangue, quando o shopper percorre apenas a metade de um corredor e retorna (UNDERHILL, 2009, p.90).

Em outras estratégias elencadas, as crianças são vistas não como iscas para os shoppers, seus pais, mas sim como os próprios alvos. As recomendações partem da premissa de que os produtos sedutores aos infantes devem estar ao alcance de suas pequenas mãos (UNDERHILL, 2009, p.163). Nesse sentido, em livrarias, os livros ou vídeos com personagens da moda, popularizados sobretudo pelos meios de comunicação de massa, devem estar nas prateiras mais baixas, ao passo que os clássicos infanto-juvenis, como $O$ pequeno príncipe, caem bem nas prateleiras superiores. Assim, a mesma estante apelará para o filho e para os pais (UNDERHILL, 2009, p.167). A lógica é simples. Um livro do Bob Esponja, facilmente alcançável, tenderá a ser melhor vendido pela própria criança, a qual, às súplicas, se encarregará de convencer o responsável.

Na obra Vamos às compras!, a atenção comercial destinada às crianças, antes de ser discutida por um prisma ético, parece ser vista como uma mostra do quão o capitalismo é "democrático".

O mercado deseja as crianças, ne- cessita delas, necessita das crianças e elas são cortejadas pelo convite e o aceitam com prazer. Hoje, elas idolatram os personagens da televisão da mesma forma que as crianças de outrora eram ensinadas a venerar os santos padroeiros $\mathrm{e}$ aprendem desde cedo a relação entre marca e status. Trata-se de mais um exemplo de como o capitalismo traz a democratização. Você não tem de ficar à margem do mercado global só por ter 1 metro e pouco de altura, não ter renda da qual se vangloriar e não ter permissão para atravessar a rua sem dar a mão à mãe. Você é uma força econômica, agora e no futuro, e é isso que conta (UNDERHILL, 2009, p. 162).

Paco Underhill dedica ainda algumas páginas ao Brasil, país no qual sua Envirosell possui um escritório licenciado - em vias de se tornar uma joint-venture. Aqui, mesmo um otimista propugnador do capitalismo, impressiona-se com a saliente desigualdade social, a qual, por si só, configura-se em uma variável indissociável de qualquer pesquisa realizada no varejo local.

Às vistas do autor, a dicotomia social brasileira é metaforicamente representada pela varejista paulista de produtos de luxo Daslu (UNDERHILL, 2009, p. 291), cuja sofisticação e ostentação o deixaram em "estado de total estupefação" (UNDERHILL, 2009, p. 289). Com seus coffee bars, champagne bars, restaurantes, grifes internacionais, serviço de cirurgia plástica, drogaria de luxo, planejador de viagens e departamento imobiliário, a Daslu parece não se importar em atrair um grande volume de compradores ou expandir o seu mercado consumidor, como, supõemse, costumam desejar os capitalistas de países desenvolvidos.

Ao contrário de alguns símbolos internacionais do varejo, como o Walmart, cuja política balizadora de ações e a de vender para o maior número de pessoas possível, o caso brasileiro da Daslu contradiz o atributo de "democrático", concedido pelo autor ao capitalismo. O próprio Underhill chega a utilizar as expressões "feudo protegido" e "clube privativo superisolado", para se referir a ilhas de compras em países em desenvolvimento, como África de Sul, Brasil e México (UNDERHILL, 2009, p.294). Talvez, tal observação - vinda de um entusiasta do consumo - endosse a iminência de reflexões sobre os anacronismos do capitalismo brasileiro.

\section{Outras referências}

JAIME JR., Pedro. Etnomarketing: antropologia, cultura e consumo. RAE - Revista de Administração de Empresas. São Paulo, v. 41, nº p. 68-77, out.- dez. 2001. Disponível em http:// www.scielo.br/pdf/rae/v41n4/v41n4a08. Acesso em 23/03/2015. 